\title{
Quantification of HIV-1 RNA Among Men Who Have Sex With Men Using an At-Home Self-Collected Dried Blood Spot Specimen: Feasibility Study
}

Sabina Hirshfield ${ }^{1 *}$, PhD; Richard A Teran ${ }^{2 *}, \mathrm{MPH}$; Martin J Downing $\mathrm{Jr}^{3}$, PhD; Mary Ann Chiasson ${ }^{2,4}$, DrPH; Hong-Van Tieu ${ }^{4,5}$, MD; Laura Dize ${ }^{6}$, MS; Charlotte A Gaydos ${ }^{6}$, MS, MPH, DrPH

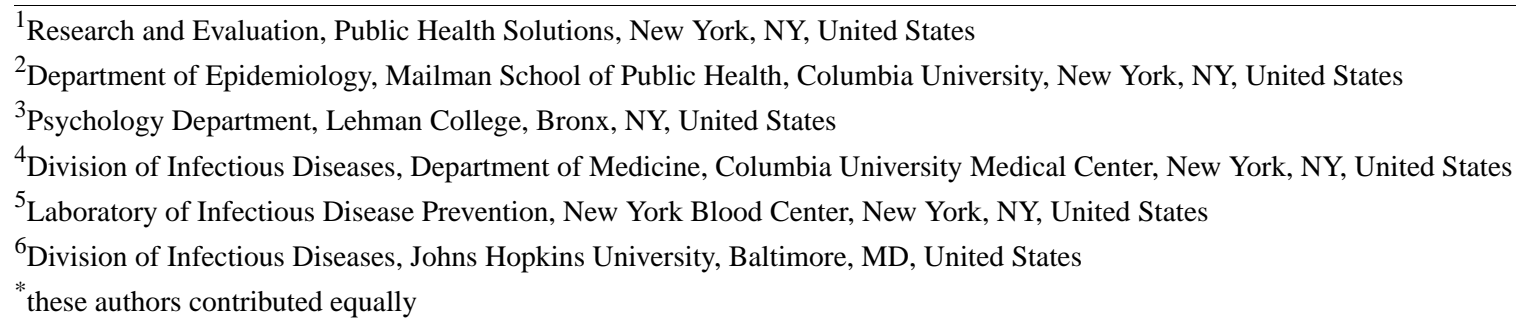

\section{Corresponding Author:}

Sabina Hirshfield, PhD

Research and Evaluation

Public Health Solutions

40 Worth Street, 5th Floor

New York, NY, 10013

United States

Phone: 16466196676

Fax: 16466196777

Email: SHirshfield@healthsolutions.org

\section{Abstract}

Background: Suboptimal antiretroviral therapy (ART) adherence and disengagement in care present significant public health challenges because of the increased probability of HIV transmission. In the United States, men who have sex with men (MSM) continue to be disproportionately affected by HIV, highlighting a critical need to engage high-risk MSM living with HIV who are not engaged or retained in care.

Objective: The aim of the study was to assess the feasibility of at-home blood self-collection and laboratory quantification of HIV-1 RNA viral load (VL) to report laboratory-based VL outcomes and compare self-reported and laboratory-reported VL

Methods: Between 2016 and 2017, 766 US HIV-positive MSM enrolled in a Web-based behavioral intervention were invited to participate in an at-home dried blood spot (DBS) collection study using HemaSpot-HF kits (Spot On Sciences, Inc, Austin, TX) for laboratory-quantified VL.

Results: Of those invited to participate, 72.3\% (554/766) enrolled in the DBS study. Most (79.2\%, 439/554) men enrolled reported attempting to collect their blood, 75.5\% (418/554) of participants mailed a DBS specimen to the research laboratory, and $60.8 \%$ (337/554) had an adequate blood sample for VL testing. Of the 337 specimens tested for VL by the laboratory, 52.5\% (177/337) had detectable VL (median: 3508 copies/mL; range: 851-1,202,265 copies/mL). Most men (83.9\%, 135/161) who returned a DBS specimen with laboratory-quantified detectable VL self-reported an undetectable VL during their last clinical visit.

Conclusions: Home collection of DBS samples from HIV-positive MSM is feasible and has the potential to support clinical VL monitoring. Discrepant laboratory HIV-1 RNA values and self-reported VL indicate a need to address perceived VL status, especially in the era of treatment as prevention. Most participants were willing to use an at-home DBS kit in the future, signaling an opportunity to engage high-risk MSM in long-term HIV care activities.

(JMIR Public Health Surveill 2018;4(4):e10847) doi: 10.2196/10847 


\section{KEYWORDS}

HIV-1; viral load; dried blood spot testing; men who have sex with men

\section{Introduction}

\section{Background}

Suboptimal antiretroviral therapy (ART) adherence and intermittent engagement in care present significant public health challenges because of the increased probability of HIV transmission resulting from high HIV-1 RNA viral load (VL) [1-5]. It is critical to assess strategies to monitor VL among individuals living with HIV who are not consistently ART adherent. In the United States, men who have sex with men (MSM) continue to be disproportionately affected by HIV; in 2016, MSM accounted for $66.79 \%(26,570 / 39,782)$ of all HIV diagnoses and $82.69 \%(26,570 / 32,131)$ of diagnoses among men [1]. Among US MSM known to be living with HIV in $2014,74.07 \%(265,280 / 358,151)$ had received any care, $57.66 \%$ $(206,523 / 358,151)$ were retained in care, and $61.16 \%$ $(219,043 / 358,151)$ of those in care achieved viral suppression, although engagement in care and viral suppression were lowest among younger MSM and black MSM [6,7]. Research and program initiatives have aimed to increase both the number of MSM who are tested and who engage in care after an HIV diagnosis [8-10]. At-home rapid HIV self-testing has provided another option for MSM to be tested, and studies have shown that MSM are willing to self-test rather than use traditional testing sites because of stigma, privacy-related concerns, and the ability to test at any time [11-13]. There is a similar need for VL self-testing or sample collection approaches to be developed for MSM living with HIV that can support traditional HIV clinical care and increase the proportion of virally suppressed MSM living with HIV.

The Mailed-Spot (M-Spot) study assessed the feasibility of home self-collection of dried blood spot (DBS) specimens for laboratory quantification of VL among US white, black, and Hispanic MSM living with HIV who participated in a Web-based behavioral intervention [14]. Because MSM commonly use the Internet and smartphone apps for sexual and health purposes, Web-based and mobile settings provide an opportunity for engagement and obtaining biologic specimens in behavioral research [15-17].

\section{Study Objectives}

We report feasibility and VL outcomes among MSM living with HIV who received a novel DBS collection kit for at-home blood self-collection and laboratory quantification of VL.

\section{Methods}

\section{Study Overview}

MSM participating in Sex Positive! (parent study), a national Web-based behavioral intervention, were invited to take part in the M-Spot study following completion of the original study. The parent study's protocol has been described previously [14]. Briefly, eligible participants in the parent study were (by self-report) biologically male and identified as a male or genderqueer; aged 18 years or older; white, black, or Hispanic; able to read and respond in English; a US resident; HIV-positive; not virally suppressed (>200 copies $/ \mathrm{mL}$ ) in the past year or reported past-month suboptimal ART adherence [18]; and had condomless anal sex with an HIV-negative or unknown status male partner in the past 6 months.

\section{Ethics Statement}

The institutional review board (IRB) at Public Health Solutions in New York, NY, approved all study procedures. The IRB at Johns Hopkins University in Baltimore, MD, approved all laboratory-related procedures. Participants provided consent by clicking a button at the end of the Web-based consent form to indicate that they had read the consent page and agreed to participate. A Certificate of Confidentiality was obtained from the National Institute of Mental Health to protect the privacy of participants enrolled in this study.

\section{Participants}

For the M-Spot study, men received an email recruitment solicitation within a week of completing the parent study's 12-month follow-up survey. The email contained a link that redirected them to a brief, secure screening survey. Those ever diagnosed with hemophilia, or who were currently taking anticoagulation medication, were excluded.

\section{Study Procedures}

Consenting participants were mailed a package containing one HemaSpot-HF device (DBS kit; Spot On Sciences, Inc, Austin, TX), collection materials (alcohol prep pads, lancets, gauze pad, and adhesive bandages), an instruction card, and a return envelope with postage. Men read the instruction card or viewed a video that demonstrated how to collect their blood and mail their DBS specimen to the International STD Research Laboratory at Johns Hopkins University.

After self-collecting a DBS specimen, men completed a brief Web-based survey (herein referred to as the M-Spot survey), which inquired about the blood collection process; experience using the kit (ie, attempts to use the kit, experience using the lancet, etc); experience with the study materials (ie, did they watch the video, did they understand the instruction card); willingness to use a DBS kit in the future; and engagement in HIV care since the parent study's 12-month follow-up survey. After collecting their blood specimen and completing the M-Spot survey, men mailed their DBS specimen to the research laboratory.

HemaSpot-HF was developed to address technical issues associated with using traditional filter cards for DBS collection [19]. A protective plastic cartridge minimizes the risk of contamination and contains a desiccant ring to keep the sample free from moisture. Immediately after blood collection, the desiccant allows the kit to be closed for shipment. Upon receipt at the laboratory, DBS specimens were stored for up to 4 months at $4^{\circ} \mathrm{C}$ before testing. If a DBS kit was half-filled with blood or not filled at all, the sample was deemed untestable. Acceptable 
samples were tested in batches corresponding to laboratory receipt date.

DBS specimens were placed in an Abbott Master Mix Tube (Abbott Molecular Inc, Des Plaines, IL) containing $1.3 \mathrm{~mL}$ of Abbott mSample Preparation system DBS Buffer (a research-use-only assay) incubated for $30 \mathrm{~min}$ at $55^{\circ} \mathrm{C}$ with gentle mixing and placed on the Abbott m2000sp instrument for sample extraction. The Abbott m2000sp/rt system used an open-mode protocol for DBS samples [20]. VL results were reported as "not detected," if no HIV-1 RNA was detected in the sample. A qualitative result of " $\leq 832$ copies/mL $(\leq 2.92 \mathrm{log}$ copies)" was reported when fewer than or equal to 832 copies/mL of HIV-1 RNA were detected. Quantitative VL results were reported when HIV-1 RNA was detectable above 832 copies/mL (2.93 log copies to $7.00 \log$ copies). A lower limit of quantification was not reported by the manufacturer as there is a low probability of reproducibility when samples have viremia $\leq 2.92 \log$ copies (832 copies/mL). On the completion of DBS specimen analysis, aggregate results from the study were emailed to all consenting participants. We did not have IRB approval to provide individual results to participants.

\section{Survey Measures}

The M-Spot survey was designed to assess the feasibility of collecting a DBS specimen for VL and also to capture HIV care information that may have occurred between the end of the parent study and enrollment in the M-Spot study. To reduce participant's burden, HIV care questions were only asked if the participant reported seeing an HIV care provider after completing the 12-month survey (see Self-Reported Viral Load Status subsection). M-Spot survey data were merged with data from the parent study's screener (herein referred to as screener) and the parent study's 12-month follow-up survey (herein referred to as the parent survey). Demographic measures were primarily collected from the screener, HIV care and adherence measures for this analysis were collected from the parent survey, and DBS feasibility questions were collected from the M-Spot survey. Median time between the completion of the screener and the M-Spot survey was 405 days (range: 367-617 days), and median time between the completion of the parent survey and the M-Spot survey was 36 days (range: 6-257 days). All survey data were collected online.

\section{Participant Characteristics}

The screener included questions on participant's age, race and ethnicity, gender identity, and sex at birth. Recruitment source was also identified from the screener, based on the recruitment URL used by the participant. Participants indicated on the parent survey whether they were diagnosed with HIV in the past year. The parent survey also obtained updated level of education, annual income, employment status, and insurance information.

\section{Sexual History}

Participants reported number of male anal insertive and receptive sex partners in the last 3 months on the parent survey. Pull-down menus listed 0 through 100 partners, 101+ partners, I don't know, and prefer not to answer.

\section{HIV Care}

To assess engagement in HIV care, men were asked on the parent survey whether they had a doctor, nurse, or other medical provider whom they considered to be in charge of their overall HIV health care. Response options included no, yes, and prefer not to answer. Participants were also asked on the parent survey when was the last time they had a health care appointment with their HIV care provider (last 3 months, 3-6 months ago, 6-9 months ago, 9-12 months ago, more than a year ago, I don't know, and prefer not to answer).

\section{Antiretroviral Medication Adherence}

Participants were asked on the parent survey about their current use of antiretroviral medications (yes, no). Among participants on treatment, past 30-day adherence to ART was assessed using a 3-item scale [18]. Participants were asked: "In the last 30 days, on how many days did you miss at least one dose of any of your HIV medicines?" (0-30 days); "In the last 30 days, how good a job did you do at taking your HIV medicines in the way you were supposed to?" (never, rarely, sometimes, usually, almost always, always); and "In the last 30 days, how often did you take your HIV medicines in the way you were supposed to?" (never, rarely, sometimes, usually, almost always, always). Responses to each question were linearly transformed to a 0 to 100 scale and averaged across all 3 items.

\section{Self-Reported Viral Load Status}

The M-Spot survey included items to measure self-reported VL status at the time of blood collection. Participants indicating an HIV care visit since the parent survey were asked whether they had a VL test. Men who reported having a VL test were asked to estimate the date of their last VL test and to select their most recent results from the following: My viral load was undetectable; My viral load was detectable; I don't know-but I think I was detectable; and I don't know-but I think I was undetectable. Participants reporting My viral load was detectable or I don't know-but I think I was detectable were categorized as having a self-reported detectable VL status. Participants reporting My viral load was undetectable or I don't know-but I think I was undetectable were categorized as having a self-reported undetectable VL status.

Data on self-reported VL status from participants who did not report an HIV care visit between the parent survey and the M-Spot study were obtained from the parent survey; men who reported a VL test in the past 6 months on the parent survey were asked to select their most recent results from the following: My viral load was undetectable, or <200 copies/mL; My viral load was detectable, or $>200$ copies/mL; I don't know-but I think I was undetectable; and I don't know-but I think I was detectable. Using the same strategy as in the M-spot survey, responses were dichotomized (detectable, undetectable). The date of the last VL test was not collected on the parent survey.

\section{Time Between Self-Reported Viral Load and Dried Blood Spot Specimen Collection}

The difference between the date of DBS specimen collection and date of self-reported VL status on the M-Spot or parent survey was used to estimate the time between a self-reported VL from a plasma sample (collected during an HIV care visit) 
and a VL laboratory result from a DBS specimen. The calendar date reported for last VL test in the M-Spot survey was used as the participant's self-reported VL date. The parent survey did not ask participants to report the date of their last VL test. Thus, for participants who did not visit their HIV care provider in between the parent study and the M-Spot study, the day they finished the parent survey was used as a proxy for the participant's self-reported VL test date. If participants did not self-report a VL status on either the M-Spot survey or parent survey, their self-reported VL status was treated as missing.

\section{Experience Using Dried Blood Spot Kit}

Experience using the DBS kit at home was measured through several questions on the M-Spot survey. Men were asked if they felt comfortable collecting their own blood sample (yes, no, prefer not to answer), and they were asked to rate their overall experience using the HemaSpot-HF device (very easy, easy, hard, very hard, prefer not to answer). Participants were also asked to rate their willingness to use a DBS kit in a future study (very willing, willing, not willing, extremely not willing, prefer not to answer).

\section{Statistical Methods}

We assessed study feasibility by the proportion of participants who successfully completed various stages: enrollment, collecting a blood sample, mailing the kit to the laboratory, laboratory receipt of DBS specimens, and providing a testable blood sample. Pearson chi-square tests, Fisher exact tests, independent-sample $t$-tests, and Mann-Whitney $U$ tests were used to identify group differences between participants who enrolled and did not enroll in the study and between participants who returned a DBS sample with detectable and undetectable viremia. Data analyses were performed using SAS version 9.4 (SAS Institute, Cary, NC).

\section{Results}

\section{Participant Characteristics}

From September 2016 to February 2017, an invitation link to participate in the M-Spot study was sent to 766 men living with HIV within a week of completing the parent survey (Figure 1, box A). Of note, 112 men had completed the parent survey before we received IRB approval and thus were not eligible to participate in the study. Among recruited men, 86.6\% (663/766) opened the email and clicked on the screener link (Figure 1, box B). Men who clicked the link were more likely to have health insurance $(93.6 \%$ [617/659] vs $88.1 \%$ [89/101], $P=.04)$ and a past 6-month HIV health care visit $(92.4 \%$ [549/594] vs $83.0 \%$ [78/94], $P<.01)$ than men who did not click the link. In total, 568 men were eligible to participate, 562 consented (Figure 1, box C), and 554 (72.3\% [554/766] of those recruited) enrolled in the study (Figure 1, box D). To enroll, participants had to provide a mailing address to receive the DBS kit by mail.

Most enrolled participants were white $(68.8 \%, 381 / 554)$, college-educated $(61.7 \%, 341 / 553)$, and had a yearly income of less than US $\$ 40,000(54.9 \%, 304 / 554$; see Table 1$)$. Median age was 39 years (range: 19-72 years). Most men (56.1\%, 332/542) enrolled in M-Spot had been recruited for the parent study from a website for men interested in condomless anal sex with a male partner. Over half $(57.8 \%, 320 / 554)$ were employed full time, and $94.0 \%$ (516/549) were insured-half through public health insurance. Participants self-reported a median of 2 male sexual partners (range: $0-101$ ) in the past 3 months. A minority of men $(19.1 \%, 105 / 551)$ were diagnosed with HIV in the 12 months before they enrolled in the parent study. On the basis of participants' self-report, $91.1 \%$ (499/548) were engaged in HIV care; $93.0 \%$ (463/498) had visited their HIV care provider in the past 6 months; and 93.3\% (516/553) were currently on ART, with a median Wilson adherence score of 88.9\% (range: $0 \%-100 \%$ ); and 90.8\% (456/502) self-reported an undetectable VL $(\leq 200$ copies $/ \mathrm{mL})$ from their last clinical laboratory test. Compared with men who did not enroll in the M-Spot study, men who enrolled were more likely to have seen their HIV care provider in the past 6 months $(93.0 \%$ [463/498] vs $86.3 \%$ [164/190], $P=.02$ ) and more likely to report ART use (93.3\% [516/553] vs $89.1 \%$ [188/211], $P=.05$; see Table 1$)$.

\section{Feasibility and Acceptability}

Of the 554 men enrolled in M-Spot, 79.2\% (439/554) reported attempting to collect their blood (Figure 1, box E). Some participants $(n=49)$ requested a second DBS kit; reasons included difficulties collecting their blood or losing the kit. Of these men, 11 had issues drawing blood with the lancet and attributed this to callused fingertips. The initial lancet used for this study had an 18-gauge blade with a 2.3 -mm penetration depth. In response to lancet-related issues, we sent the 11 participants, and all subsequently enrolled participants, lancets that had a 21-gauge needle and 2.8-mm penetration depth.

A high proportion $(75.5 \%, 418 / 554)$ mailed a DBS specimen to the laboratory (Figure 1, box F). The laboratory received and evaluated 413 kits (Figure 1, box G). The median time between sample collection and specimen receipt was 4 days (range: 1-69 days). Among the kits received, 76 were not analyzed: 65 had an inadequate amount of blood and were deemed untestable, an instrument error occurred when processing 7 specimens, and an internal control error occurred when processing 4 specimens. In total, 337 kits had a sufficient amount of blood and were tested (Figure 1, box $\mathrm{H}$ ).

Among men who returned a DBS specimen to the laboratory and completed the study survey, 89.8\% (326/363) reported feeling comfortable collecting their blood; $83.6 \%$ (306/366) rated their experience using the DBS kit as "very easy" or "easy," and $98.1 \%$ (357/364) reported willingness to use an at-home DBS kit in the future.

Among 115 participants who did not attempt to use the DBS kit, 105 men received the kit but did not participate (ie, were lost to follow-up), 7 men withdrew from the study, 2 men never received the kit, and 1 participant decided not to use the kit after opening the package. The men who were lost to follow-up or withdrew were predominantly white $(69.6 \%, 80 / 115)$, college-educated $(58.3 \%, 67 / 115)$, earned less than US $\$ 40,000$ $(57.1 \%, 64 / 112)$, and had a lower Wilson ART adherence score $(81 \%$ vs $85 \% ; P=.04)$ than men participating in study activities. Finally, 15 participants were unable to collect their blood and did not mail their kit. 
Figure 1. M-Spot study recruitment and participation. M-Spot: Mailed-Spot.

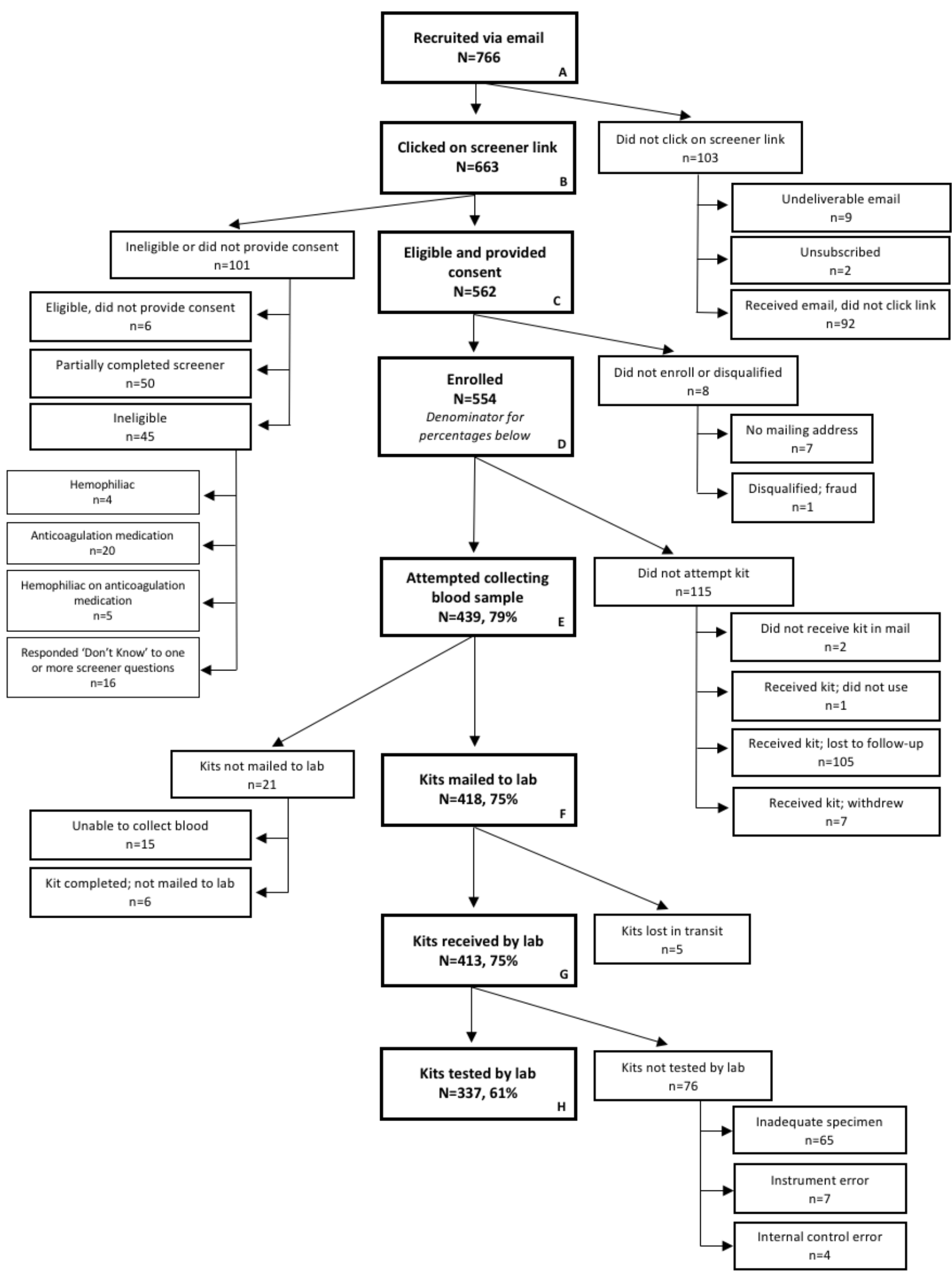


Table 1. Sociodemographic and behavioral characteristics of recruited participants, by enrollment status (N=766).

\begin{tabular}{|c|c|c|c|c|}
\hline Characteristics & Total $(\mathrm{N}=766)$ & Enrolled $(\mathrm{n}=554)$ & Ineligible or not enrolled $(\mathrm{n}=212)$ & $P$ value \\
\hline Age in years $(n=765)^{a}, n(\%)$ & & & & $.10^{\mathrm{b}}$ \\
\hline $18-29$ & $155(20.3)$ & $111(20.1)$ & $44(20.8)$ & \\
\hline $30-39$ & $233(30.5)$ & $181(32.7)$ & $52(24.5)$ & \\
\hline $40-49$ & $221(28.9)$ & $159(28.8)$ & $62(29.3)$ & \\
\hline $50-59$ & $126(16.5)$ & $84(15.2)$ & $42(19.8)$ & \\
\hline$\geq 60$ & $30(3.9)$ & $18(3.3)$ & $12(5.7)$ & \\
\hline Race $(n=766), n(\%)$ & & & & $.31^{\mathrm{b}}$ \\
\hline Black & $124(16.2)$ & $83(15.0)$ & $41(19.3)$ & \\
\hline Hispanic & $120(15.7)$ & $90(16.3)$ & $30(14.2)$ & \\
\hline White & $522(68.2)$ & $381(68.8)$ & $141(66.5)$ & \\
\hline Education $(n=763)^{\mathrm{a}}, \mathrm{n}(\%)$ & & & & $.55^{\mathrm{b}}$ \\
\hline High school diploma or less & $68(8.9)$ & $53(9.6)$ & $15(7.1)$ & \\
\hline Some college & $224(29.4)$ & $159(28.8)$ & $65(31.0)$ & \\
\hline College graduate & $309(40.5)$ & $228(41.2)$ & $81(38.6)$ & \\
\hline Professional or graduate degree & $162(21.2)$ & $113(20.4)$ & $49(23.3)$ & \\
\hline Income $(n=743)^{a}, n(\%)$ & & & & $.21^{\mathrm{b}}$ \\
\hline$<\$ 20,000$ & $225(30.3)$ & $173(31.9)$ & $52(25.9)$ & \\
\hline$\$ 20,000-\$ 39,999$ & $182(24.5)$ & $131(24.2)$ & $51(25.4)$ & \\
\hline$\$ 40,000-\$ 59,999$ & $137(18.4)$ & $102(18.8)$ & $35(17.4)$ & \\
\hline$\$ 60,000-\$ 99,999$ & $111(14.9)$ & $80(14.8)$ & $31(15.4)$ & \\
\hline$\geq \$ 100,000$ & $88(11.8)$ & $56(10.3)$ & $32(15.9)$ & \\
\hline Insured $(\mathrm{n}=757)^{\mathrm{a}}, \mathrm{n}(\%)$ & & & & $.41^{\mathrm{b}}$ \\
\hline Yes, private health insurance & $349(46.1)$ & $257(46.8)$ & $92(44.2)$ & \\
\hline Yes, public health insurance & $357(47.2)$ & $259(47.2)$ & $98(47.1)$ & \\
\hline No & $51(6.7)$ & $33(6.0)$ & $18(8.7)$ & \\
\hline Employed full time (n=766), $\mathrm{n}(\%)$ & $443(57.8)$ & $320(57.8)$ & $123(58.0)$ & $.95^{\mathrm{b}}$ \\
\hline Recruitment source $(n=764)^{a}, n(\%)$ & & & & $.44^{\mathrm{b}}$ \\
\hline Mobile phone app & $234(30.6)$ & $170(30.7)$ & $64(30.3)$ & \\
\hline Bareback website & $453(53.3)$ & $332(60.0)$ & $121(57.4)$ & \\
\hline Other sites & $77(10.1)$ & $51(9.2)$ & $26(12.3)$ & \\
\hline Engaged in HIV care $(\mathrm{n}=758)^{\mathrm{a}}, \mathrm{n}(\%)$ & $689(90.9)$ & $499(91.1)$ & $190(90.5)$ & $.80^{\mathrm{b}}$ \\
\hline Currently on antiretroviral therapy $(\mathrm{n}=764)^{\mathrm{a}}, \mathrm{n}(\%)$ & $704(92.2)$ & $516(93.3)$ & $188(89.1)$ & $.05^{\mathrm{c}}$ \\
\hline Past year HIV diagnosis $(\mathrm{n}=762)^{\mathrm{a}}, \mathrm{n}(\%)$ & $151(19.8)$ & $105(19.1)$ & $46(21.8)$ & $.39^{\mathrm{a}}$ \\
\hline Last HIV care visit $(n=688)^{a}, n(\%)$ & & & & $.02^{\mathrm{b}, \mathrm{c}}$ \\
\hline$<6$ months & $627(91.1)$ & $463(93.0)$ & $164(86.3)$ & \\
\hline 6-12 months & $51(7.4)$ & $29(5.8)$ & $22(11.6)$ & \\
\hline$>12$ months & $10(1.5)$ & $6(1.2)$ & $4(2.1)$ & \\
\hline Self-reported HIV viral load status $(n=673)^{\mathbf{a}}, \mathbf{n}(\%)$ & & & & $.18^{\mathrm{b}}$ \\
\hline Undetectable & $617(91.7)$ & $456(90.8)$ & $161(94.5)$ & \\
\hline Detectable & $56(8.3)$ & $46(9.2)$ & $10(5.9)$ & \\
\hline
\end{tabular}




\begin{tabular}{lllll}
\hline Characteristics & Total $(\mathrm{N}=766)$ & Enrolled $(\mathrm{n}=554)$ & Ineligible or not enrolled $(\mathrm{n}=212)$ & $P$ value \\
\hline Antiretroviral therapy adherence score, mean $(\mathrm{n}=703)^{\mathrm{a}}$ & 84.5 & 84.6 & 84.3 & $.88^{\mathrm{d}}$ \\
Number of male anal sex partners, last 3 months, mean $(\mathrm{n}=766)$ & 18.3 & 21.2 & 10.5 & $.56^{\mathrm{e}}$ \\
\hline
\end{tabular}

${ }^{\mathrm{a}}$ Denominators vary because of missing data.

${ }^{\mathrm{b}}$ Pearson chi-square test.

${ }^{\mathrm{c}}$ Statistical significance at level $P \leq .05$.

${ }^{\mathrm{d}}$ Independent-sample $t$ test.

${ }^{\mathrm{e}}$ Mann-Whitney $U$ test.

\section{Viral Load Results}

Of the 337 specimens tested for VL by the laboratory, over half $(52.5 \%, 177 / 337)$ had detectable VL, whereas $47.5 \%(160 / 337)$ of participants returned a sample with no detectable HIV-1 RNA (Figure 2). Of the DBS specimens classified as having a detectable VL, a total of 99 DBS specimens from participants had a qualitative result of " $\leq 832$ copies $/ \mathrm{mL}$ ( $\leq 2.92 \log$ copies)," and 78 DBS specimens had a quantitative result of $>832$ copies/mL. Among the DBS specimens with a quantitative VL $(\mathrm{n}=78)$, the overall median $\mathrm{VL}$ was 3508 copies/mL (interquartile range, IQR: 1349-21,754 copies/mL). When stratified into different levels of viremia, 9 specimens had detectable viremia between 833 and 999 copies/mL (median:
891 copies/mL; IQR: 870-955 copies/mL), 43 specimens were between 1000 and 9999 copies/mL (median: 1995 copies/mL; IQR: $1349-4542$ copies/mL), and 26 specimens had viremia $\geq 10,000$ copies/mL (median: 46,823 copies/mL; IQR: 22,264-144,865 copies/mL; see Figure 2). Compared with participants who returned a DBS specimen with detectable viremia, men who returned a DBS specimen with undetectable viremia were significantly more likely to be employed full-time $(63.1 \%$ [101/160] vs 52.5\% [93/177], $P=.05)$, report a recent HIV diagnosis (<1 year; $23.1 \%$ [37/160] vs $12.5 \%$ [22/176], $P=.01)$, be engaged in HIV care $(96.9 \%$ [155/160] vs $86.4 \%$ [152/176], $P<.01)$, and be currently on ART (98.8\% [158/160] vs $88.6 \%$ [156/176], $P<.01$; see Table 2).

Figure 2. Participant laboratory HIV-1 RNA results, $n=337$.

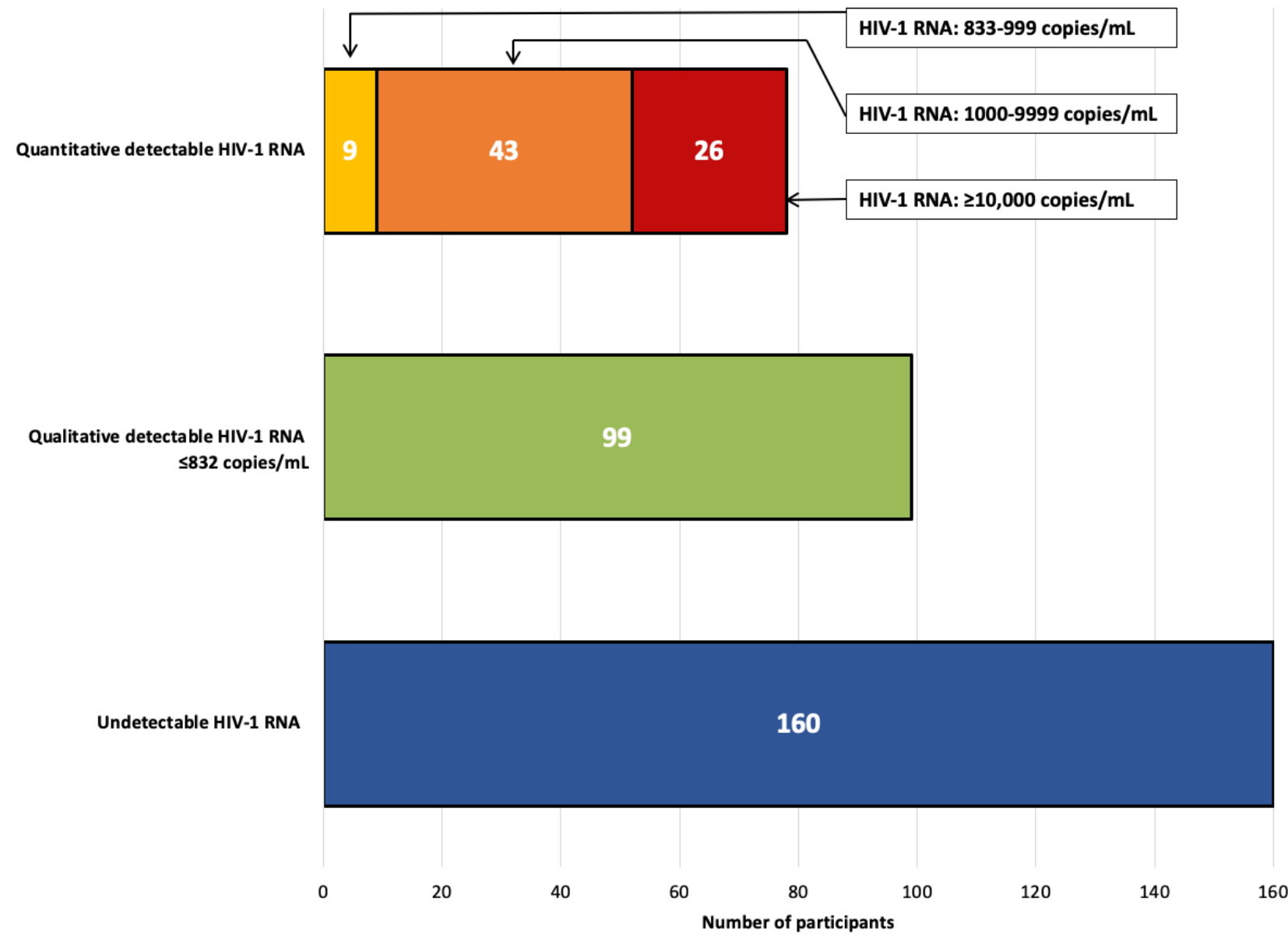


Table 2. Characteristics of participants who provided a testable dried blood spot specimen, by HIV-1 RNA viral load status ( $\mathrm{n}=337$ ).

\begin{tabular}{|c|c|c|c|c|}
\hline Characteristics & Total $(n=337)$ & Detectable HIV-1 RNA ${ }^{\mathrm{a}},(\mathrm{n}=177)$ & Undetectable HIV-1 RNA ${ }^{\mathrm{a}},(\mathrm{n}=160)$ & $P$ value \\
\hline Age in years $(n=337), n(\%)$ & & & & $.28^{\mathrm{b}}$ \\
\hline $18-29$ & $69(20.5)$ & $34(19.2)$ & 35 (21.9) & \\
\hline $30-39$ & $116(34.4)$ & $55(31.1)$ & $61(38.1)$ & \\
\hline $40-49$ & $91(27.0)$ & $55(31.1)$ & $36(22.5)$ & \\
\hline$\geq 50$ & $61(18.1)$ & $33(18.6)$ & $28(17.5)$ & \\
\hline Race $(n=337), n(\%)$ & & & & $.99^{\mathrm{b}}$ \\
\hline Black & $41(12.2)$ & $22(12.4)$ & $19(11.9)$ & \\
\hline Hispanic & $57(16.9)$ & $30(17.0)$ & $27(16.9)$ & \\
\hline White & $239(70.9)$ & $125(70.6)$ & $114(71.3)$ & \\
\hline Employed full-time $(\mathrm{n}=337), \mathrm{n}(\%)$ & $194(54.6)$ & $93(52.5)$ & $101(63.1)$ & $.05^{\mathrm{b}, \mathrm{c}}$ \\
\hline Insured $(n=333)^{d}, n(\%)$ & & & & $.60^{\mathrm{b}}$ \\
\hline Yes, private health insurance & $158(47.5)$ & $79(44.9)$ & $79(50.3)$ & \\
\hline Yes, public health insurance & $154(46.3)$ & $85(48.3)$ & $69(44.0)$ & \\
\hline No & $21(6.3)$ & $12(6.8)$ & $9(5.7)$ & \\
\hline Past year HIV diagnosis $(\mathrm{n}=335)^{\mathrm{d}}, \mathrm{n}(\%)$ & $59(17.6)$ & $22(12.5)$ & $37(23.3)$ & $.01^{\mathrm{b}, \mathrm{c}}$ \\
\hline Engaged in HIV care $(n=336)^{d}, n(\%)$ & $307(91.4)$ & $152(86.4)$ & $155(96.9)$ & $.001^{\mathrm{b}, \mathrm{c}}$ \\
\hline Last HIV care visit $(n=307)^{d}, n(\%)$ & & & & $.60^{\mathrm{e}}$ \\
\hline$<6$ months & $286(93.2)$ & $140(92.1)$ & $146(94.2)$ & \\
\hline 6-12 months & $17(5.5)$ & $9(5.9)$ & $8(5.2)$ & \\
\hline$>12$ months & $4(1.3)$ & $3(2.0)$ & $1(0.7)$ & \\
\hline \multicolumn{4}{|c|}{ Self-reported HIV viral load status $(n=316)^{d}, n(\%)$} & $<.001^{\mathrm{b}, \mathrm{c}}$ \\
\hline Undetectable & $284(89.9)$ & $135(83.9)$ & $149(96.1)$ & \\
\hline Detectable & $32(10.1)$ & $26(16.2)$ & $6(3.9)$ & \\
\hline Currently on $\operatorname{ART}^{\mathrm{f}}(\mathrm{n}=336)^{\mathrm{d}}, \mathrm{n}(\%)$ & $314(93.5)$ & $156(88.6)$ & $158(98.8)$ & $<.001^{\mathrm{b}, \mathrm{c}}$ \\
\hline ART adherence score, mean $(n=313)^{d}$ & 85.5 & 84.4 & 86.5 & $.33^{\mathrm{g}}$ \\
\hline $\begin{array}{l}\text { Number of male anal sex partners (mean), } \\
\text { last } 3 \text { months }(n=337)\end{array}$ & 26.5 & 29.8 & 22.9 & $.63^{\mathrm{h}}$ \\
\hline
\end{tabular}

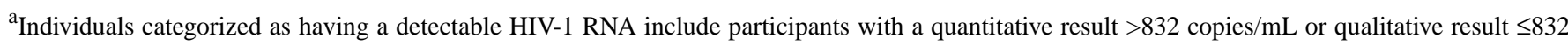
copies/mL.

${ }^{\mathrm{b}}$ Pearson chi-square test.

${ }^{\mathrm{c}}$ Statistical significance at level $P \leq .05$.

${ }^{\mathrm{d}}$ Denominators vary because of missing data.

${ }^{\mathrm{e}}$ Fisher exact test.

${ }^{f}$ ART: antiretroviral therapy.

g Independent-sample $t$ test.

${ }^{\mathrm{h}}$ Mann-Whitney $U$ test. 
Figure 3. Participant self-reported viral load status, by laboratory HIV-1 RNA result, $n=316$.

Detectable HIV-1 RNA ( $\geq 10,000$ copies/mL), n=1

Detectable HIV-1 RNA (1000-9999 copies/mL), n=39

Detectable HIV-1 RNA (<1000 copies/mL), n=105

Undetectable HIV-1 RNA, n=155

$24 \%$

$76 \%$

Overall, $n=316$

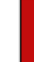

$0 \%$

Discrepant self-reported viral load
$4 \%$
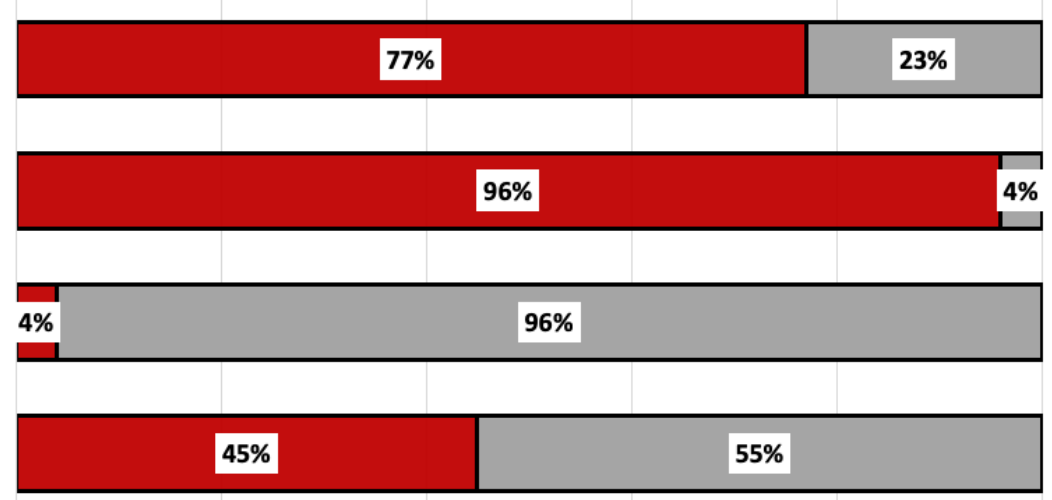

$40 \% \quad 60 \%$

$80 \%$

$100 \%$

$\square$ Nondiscrepant self-reported viral load

We compared participants' laboratory HIV-1 RNA result with their most recent self-reported VL. Among participants who returned a testable DBS specimen, 93.8\% (316/337) also self-reported their VL in the M-Spot survey or the parent survey. Among the 316 DBS samples, 284 self-reported having an undetectable VL and 32 self-reported having a detectable VL. Among men with both laboratory and self-reported VL data, 44.6\% (141/316) had a discrepant laboratory HIV-1 RNA result and self-reported VL status (Figure 3).

Of note, $83.9 \%(135 / 161)$ of the men who returned a DBS specimen with a detectable HIV-1 RNA result self-reported that they had an undetectable VL at their last clinical visit (Table 2). Among men self-reporting an undetectable VL, those living with HIV for $>1$ year at the start of the parent study were more likely to have a discrepant self-reported $\mathrm{VL}$ and a laboratory-quantified VL (88.2\% [119/135] vs 77.0\% [114/148]; $P=.01)$. However, those who self-reported being engaged in care were less likely to have discrepancies between their self-reported VL and laboratory-quantified VL compared with those who self-reported not being engaged in care $(91.1 \%$ [123/135] vs $97.3 \%$ [145/149]; $P=.02)$.

Median time between a discrepant self-reported VL and a laboratory-quantified VL was 22 days. Median time between concordant self-reported VL and a laboratory-quantified VL was 25 days. Different proportions of discrepant self-reported VL were observed when the HIV-1 RNA results from the DBS specimens were disaggregated: $96.2 \%(101 / 105)$ of men with a laboratory HIV-1 RNA result $<1000$ copies/mL, $76.9 \%$ (30/39) of men with a laboratory HIV-1 RNA result $<10,000$, and $23.5 \%$ (4/17) of men with a laboratory HIV-1 RNA result $\geq 10,000$ copies $/ \mathrm{mL}$ had a discrepant self-reported VL (Figure 3 —indicated in red). Finally, an additional 21 participants returned a testable DBS specimen but did not self-report their $\mathrm{VL}$ in the survey. Of these men, 16 returned a sample with detectable viremia; of these, 13 men had a VL > 1000 copies/mL (median: 20,893 copies/mL; range: 3467-154,881 copies/mL).

\section{Discussion}

\section{Principal Findings}

This study assessed the feasibility and acceptability of an at-home DBS collection kit for laboratory VL quantification from US MSM living with HIV who had previously reported suboptimal ART adherence or a detectable VL. To our knowledge, this is the first DBS home collection study from a Web-based sample of MSM living with HIV who mailed a DBS specimen to a laboratory for VL quantification. Feasibility was demonstrated at multiple study stages: $72.3 \%$ (554/766) of recruited men enrolled; $79.2 \%$ (439/554) of enrolled men attempted to collect a blood sample; $75.5 \%$ (418/554) mailed their DBS specimen to the laboratory and were received by the laboratory; and $60.8 \%$ (337/554) provided a testable blood sample. Among participants who returned a kit with a testable 
blood sample, $52.5 \%$ (177/337) had a detectable VL. Of significance, $83.9 \%(135 / 161)$ of DBS specimens with a detectable VL were from men who self-reported that they had an undetectable VL at their last clinical visit. These results suggest that at-home DBS collection for laboratory-quantified VL is both feasible and acceptable and may serve as a VL monitoring platform for MSM.

Our results support the findings of other studies with respect to the acceptability of self-collecting biologic specimens[21-23] and the willingness of MSM to self-collect blood samples for HIV testing [24-28]. The traditional DBS sampling using Guthrie cards or filter paper disks has been used for more than 40 years [29-31] and is now common in epidemiologic studies $[32,33]$. DBS sampling has been used in nonclinical settings for quantifying VL to identify acute and undiagnosed HIV infections [34,35]. However, DBS collection in nonclinical settings for VL quantification in known HIV-positive cohorts has largely been unexplored until now.

Results from 3 recent studies [36-38] prompted the Centers for Disease Control and Prevention and the National Institute of Allergy and Infectious Diseases to declare that people on ART who have an undetectable VL have no risk of transmitting the virus to HIV-negative partners $[39,40]$. To prevent further HIV transmission, individuals diagnosed with HIV must be engaged in care, take ART as prescribed, and achieve and maintain viral suppression [36,41]. The "Undetectable=Untransmittable" campaign has the potential to promote the benefits of HIV treatment, help alleviate stigma, and prevent further HIV transmission [42]. However, for the campaign to be effective, an individual's perceived undetectable VL status must accurately match their actual VL status. The high proportion of individuals with a discrepant laboratory HIV-1 RNA result and self-reported VL status reported in this study indicates that men either incorrectly perceived or falsely reported their actual VL status. A recent study of young MSM and transgender women living with HIV [43] similarly reports discrepant self-reported VL survey data with laboratory-based and electronic medical record VL measurements; approximately a third of participants had discrepant laboratory-measured VL and a self-reported VL status. Our study reports a much higher proportion (84\% vs $34 \%$ ) of men with discrepant VL data with differences likely because of 2 disparate study populations with different age and racial and ethnic distributions and recruitment methodologies. We echo the authors' concerns that discrepancies between self-reported and laboratory VL data have significant ramifications for continued HIV transmission, validity of epidemiological studies (eg, data misclassification), and the success of public health campaigns. Furthermore, inaccurate perception of one's VL status may have potential consequences for partner-seeking behaviors among HIV-positive MSM who believe that they are undetectable when they are not.

Although most men returned a DBS specimen with a testable blood sample, some participants experienced issues collecting their blood at home. We estimate that about $15 \%$ to $20 \%$ of participants had difficulties with the lancets provided with the DBS kit based on our email and phone communication with the participants. In addition, some reported difficulties depositing blood drops into the middle of the application surface, which prevented them from getting enough blood on the absorbent paper. Participants experiencing issues often requested a second kit (where we provided a different lancet with a deeper penetration depth), did not return their kit to the laboratory, or returned a kit to the laboratory with little or no blood. Future studies should anticipate possible specimen self-collection issues or issues with study materials such as lancets. Addressing these issues will likely increase the feasibility of at-home specimen collection.

Novel interventions, devices (eg, Food and Drug Administration-approved home VL test), and service delivery options (eg, sharing DBS VL laboratory results with a patient's provider) must be developed to increase the number of individuals who are retained in care and who achieve and accurately perceive their current VL status. An individual's VL is dynamic and viral "blips" can occur throughout the long-term treatment of HIV because of fluctuations in ART adherence or concurrent illnesses [44-47]. Individuals with a history of intermittent HIV care or detectable viremia may be more inclined to reengage in care or improve ART adherence, if they know they have a detectable (laboratory-quantified) VL from an at-home self-collected specimen; future studies should assess this, as well as whether there are clinical benefits with more frequent VL monitoring in between clinical visits from samples collected outside of clinical settings.

\section{Limitations}

A few study limitations should be acknowledged. First, with respect to our email recruitment approach, it is possible that some participants never saw the email in their inbox or spam folder. Second, $20.8 \%$ (115/554) of enrollees did not complete study activities; participants who withdrew or were lost to follow-up had a lower Wilson ART adherence score than those who attempted or completed study activities. It is possible that these participants chose not to collect their blood sample after reading the instructions, or they never opened the DBS package with study materials. It is also possible that participants who reported suboptimal ART adherence did not want to provide a blood sample that would show a detectable VL. Third, the study population was recruited from a sample of men who successfully completed a 12-month Web-based intervention. Perhaps these participants are more likely to complete a study such as M-Spot compared with other populations. Different study participation rates may be observed when collecting DBS specimens from other populations. Fourth, we did not collect a calendar date for the most recent VL test on the parent survey, limiting our ability to accurately estimate the time between an individual's plasma VL test result and DBS VL test result.

As with most DBS studies, there is concern about the correlation between a DBS specimen and laboratory result from a VL test from a plasma sample collected in a clinical setting. Several studies [48-50] have documented the high correlation between VL measurements obtained from DBS samples and those obtained from plasma, as well as the stability of samples stored under different conditions and for different time frames. In addition, stability of HIV serological markers in samples collected using the HemaSpot device has been reported and compared with DBS samples collected using the traditional 
Whatman 903 cards [51]. Similarly, studies assessing the performance of the Abbott Real-Time HIV-1 assay, used for this study, have also reported a high correlation between VL measurements from DBS and plasma samples, with $99.4 \%$ of cases differing by $<1.0$ log copies in one study [52], and a mean difference of $0.29 \mathrm{log}$ copies in another [53]. The Abbott assay and extraction method have been updated and improved frequently; this study used the most up-to-date open mode protocol available from the manufacturer. Dize et al performed validation of DBS specimens collected using HemaSpot devices compared with plasma samples [54]. Concordance analysis showed $100 \%$ agreement between samples with VL $\geq 1000$ copies/mL and $86 \%$ agreement between samples with VL $<1000$ copies/mL. Finally, we acknowledge the possibility that intracellular nucleic acid contribution at low levels of viremia may explain our DBS specimen laboratory results and the discordance between self-reported VL status and DBS specimen VL results. Other studies have reported false-positive rates ranging from $6 \%$ to $13 \%$ in which DBS samples yielded detectable VL, whereas the plasma sample had undetectable VL, with the discrepancy attributed to a possible contribution of intracellular RNA that might be present in white blood cells in whole blood [55-58]. However, it is unlikely that intracellular nucleic acid led to misclassification of VL results for participants who had high HIV VL results from their DBS specimen. Further research is needed to identify the extent to which intracellular nucleic acid influences VL results from DBS specimens collected using the HemaSpot-HF device, especially in those with low detectable HIV VL levels.

\section{Conclusions}

Despite these limitations, findings from this study highlight the feasibility and acceptability of HIV-1 RNA quantification of home-collected DBS samples from MSM living with HIV. Individuals with a history of suboptimal ART adherence and/or detectable viremia, such as those in this study, may benefit from at-home VL monitoring as a tool to augment engagement in HIV care. Home collection of DBS for VL could be utilized as a monitoring tool in between clinical visits for patients who struggle with adherence. Research on complementary systems of clinical care should be expanded and further studied, especially in the era of treatment as prevention.

\section{Acknowledgments}

This study was supported by a grant from the National Institute of Mental Health (R01-MH100973-03S1) to SH, principal investigator. RT was supported by a pre-doctoral fellowship in the Global HIV Implementation Science Research training program sponsored by the Mailman School of Public Health, Columbia University, with funding from the National Institute of Allergy and Infectious Diseases (T32 AI114398, PI: Howard). The authors would like to thank Steven Houang, Irene Yoon, and Dayana Bermudez for their contributions to study enrollment, data collection, and retention activities.

\section{Conflicts of Interest}

None declared.

\section{References}

1. Centers for Disease Control and Prevention. Cdc.gov. 2016. HIV Surveillance Report, 2016. Diagnoses of HIV Infection in the United States and Dependent Areas, 2016 URL: https://www.cdc.gov/hiv/pdf/library/reports/surveillance/ cdc-hiv-surveillance-report-2016-vol-28.pdf [accessed 2018-04-18] [WebCite Cache ID 6ymJHj4a0]

2. National Institutes of Health. FY 2017 Trans-NIH Plan for HIV-Related Research URL: https://www.oar.nih.gov/ strategic plan/fy2017/OARStrategicPlan2017.pdf [accessed 2018-04-18] [WebCite Cache ID 6ymJlji8K]

3. Centers for Disease Control and Prevention, Health Resources and Services Administration, National Institutes of Health, American Academy of HIV Medicine, Association of Nurses in AIDS Care, International Association of Providers of AIDS Care, the National Minority AIDS Council, Urban Coalition for HIV/AIDS Prevention Services. Stacks.cdc.gov. 2014 Dec 11. Recommendations for HIV Prevention with Adults and Adolescents with HIV in the United States URL: https://stacks. cdc.gov/view/cdc/44064 [accessed 2018-04-18] [WebCite Cache ID 6ymJzHOXL]

4. Hall HI, Tang T, Johnson AS, Espinoza L, Harris N, McCray E. Timing of linkage to care after HIV diagnosis and time to viral suppression. J Acquir Immune Defic Syndr 2016 Dec 1;72(2):e57-e60. [doi: 10.1097/QAI.0000000000000989] [Medline: 26977745]

5. Mujugira A, Celum C, Coombs RW, Campbell JD, Ndase P, Ronald A, Partners PrEP Study Team. HIV transmission risk persists during the first 6 months of antiretroviral therapy. J Acquir Immune Defic Syndr 2016 Aug 15;72(5):579-584 [FREE Full text] [doi: 10.1097/QAI.0000000000001019] [Medline: 27070123]

6. Hall HI, Song R, Tang T, An Q, Prejean J, Dietz P, et al. HIV trends in the United States: diagnoses and estimated incidence. JMIR Public Health Surveill 2017 Feb 3;3(1):e8 [FREE Full text] [doi: 10.2196/publichealth.7051] [Medline: 28159730]

7. Singh S, Mitsch A, Wu B. HIV care outcomes among men who have sex with men with diagnosed HIV infection - United States, 2015. MMWR Morb Mortal Wkly Rep 2017 Sep 22;66(37):969-974 [FREE Full text] [doi:

10.15585/mmwr.mm6637a2] [Medline: 28934185]

8. National Institutes of Health, Office of AIDS Research. Grants.nih.gov. 2015. NIH HIV/AIDS Research Priorities and Guidelines for Determining AIDS Funding URL: https://grants.nih.gov/grants/guide/notice-files/NOT-OD-15-137.html [accessed 2018-04-18] [WebCite Cache ID 6ymKmTUkr] 
9. Centers for Disease Control and Prevention. Cdc.gov. 2017. Division of HIV/AIDS Prevention Strategic Plan 2017 - 2020 URL: https://www.cdc.gov/hiv/pdf/dhap/cdc-hiv-dhap-external-strategic-plan.pdf [accessed 2018-04-18] [WebCite Cache ID 6ymKumana]

10. The White House. Files.hiv.gov. 2015 Jul. National HIV/AIDS Strategy for the United States: Updated to 2020 URL: https:/ /files.hiv.gov/s3fs-public/nhas-update.pdf [accessed 2018-04-18] [WebCite Cache ID 6ymL01PXt]

11. Sharma A, Sullivan PS, Khosropour CM. Willingness to take a free home HIV test and associated factors among Internet-using men who have sex with men. J Int Assoc Physicians AIDS Care (Chic) 2011;10(6):357-364 [FREE Full text] [doi: 10.1177/1545109711404946] [Medline: 21527425]

12. Hall EW, Ricca AV, Khosropour CM, Sullivan PS. Capturing HIV incidence among MSM through at-home and self-reported facility-based testing. J Acquir Immune Defic Syndr 2017 Dec 15;75(5):e142-e144. [doi: 10.1097/QAI.0000000000001338] [Medline: 28277488]

13. Gilbert M, Hottes TS, Kerr T, Taylor D, Fairley CK, Lester R, et al. Factors associated with intention to use internet-based testing for sexually transmitted infections among men who have sex with men. J Med Internet Res 2013;15(11):e254. [Medline: 24240644]

14. Hirshfield S, Downing MJ, Parsons JT, Grov C, Gordon RJ, Houang ST, et al. Developing a video-based eHealth intervention for HIV-positive gay, bisexual, and other men who have sex with men: study protocol for a randomized controlled trial. JMIR Res Protoc 2016 Jun 17;5(2):e125 [FREE Full text] [doi: 10.2196/resprot.5554] [Medline: 27315764]

15. Grov C, Breslow AS, Newcomb ME, Rosenberger JG, Bauermeister JA. Gay and bisexual men's use of the internet: research from the 1990s through 2013. J Sex Res 2014;51(4):390-409 [FREE Full text] [doi: 10.1080/00224499.2013.871626] [Medline: 24754360]

16. Hirshfield S, Grov C, Parsons J, Anderson I, Chiasson M. Social media use and HIV transmission risk behavior among ethnically diverse HIV-positive gay men: results of an online study in three U.S. states. Arch Sex Behav 2015;44(7):1969-1978. [doi: 10.1007/s10508-015-0513-5] [Medline: 26179596]

17. Liau A, Millett G, Marks G. Meta-analytic examination of online sex-seeking and sexual risk behavior among men who have sex with men. Sex Transm Dis 2006 Sep;33(9):576-584. [doi: 10.1097/01.olq.0000204710.35332.c5] [Medline: $\underline{16540884]}$

18. Wilson IB, Lee Y, Michaud J, Fowler FJ, Rogers WH. Validation of a new three-item self-report measure for medication adherence. AIDS Behav 2016;20(11):2700-2708 [FREE Full text] [doi: 10.1007/s10461-016-1406-x] [Medline: 27098408]

19. Spotonsciences. HemaSpot-HF Blood Collection Device URL: https://www.spotonsciences.com/products/hemaspot-hf/ [accessed 2018-04-18] [WebCite Cache ID 6ymLq420A]

20. Arredondo M, Garrido C, Parkin N, Zahonero N, Bertagnolio S, Soriano V, et al. Comparison of HIV-1 RNA measurements obtained by using plasma and dried blood spots in the automated abbott real-time viral load assay. J Clin Microbiol 2012 Mar;50(3):569-572 [FREE Full text] [doi: 10.1128/JCM.00418-11] [Medline: 22170904]

21. Tenover FC, Jo Baron E, Gaydos CA. Self-collected specimens for infectious disease testing. Clin Microbiol Newsl 2017 Apr;39(7):51-56. [doi: 10.1016/i.clinmicnews.2017.03.004]

22. Gaydos CA, Dwyer K, Barnes M, Rizzo-Price PA, Wood BJ, Flemming T, et al. Internet-based screening for Chlamydia trachomatis to reach non-clinic populations with mailed self-administered vaginal swabs. Sex Transm Dis 2006 Jul;33(7):451-457. [doi: 10.1097/01.olq.0000200497.14326.fb] [Medline: 16652069]

23. Lee K, Ramroop R, Gaydos C, Barnes P, Anderson J, Coleman J. Home HPV self-collection in HIV-infected women: assessing acceptability and prevalence 13M. Obstet Gynecol 2017 May;129(5):S135-S136. [doi:

10.1097/01.AOG.0000514684.83298.09]

24. Spielberg F, Critchlow C, Vittinghoff E, Coletti AS, Sheppard H, Mayer KH, et al. Home collection for frequent HIV testing: acceptability of oral fluids, dried blood spots and telephone results. HIV Early Detection Study Group. AIDS 2000 Aug 18;14(12):1819-1828. [Medline: 10985320]

25. Sharma A, Stephenson RB, White D, Sullivan PS. Acceptability and intended usage preferences for six HIV testing options among internet-using men who have sex with men. Springerplus 2014;3:109 [FREE Full text] [doi: 10.1186/2193-1801-3-109] [Medline: 24600551]

26. van Loo IH, Dukers-Muijrers NH, Heuts R, van der Sande MA, Hoebe CJ. Screening for HIV, hepatitis B and syphilis on dried blood spots: a promising method to better reach hidden high-risk populations with self-collected sampling. PLoS One 2017;12(10):e0186722 [FREE Full text] [doi: 10.1371/journal.pone.0186722] [Medline: 29053737]

27. Chavez PR, Wesolowski LD, Owen M, Gravens L, Sullivan P, MacGowan R. Perceptions and performance of self-administered rapid HIV tests conducted by untrained users in real world settings. 2016 Mar 23 Presented at: HIV Diagnostics Conference; 2016; Atlanta, GA p. 21-24.

28. Ricca AV, Hall EW, Khosropour CM, Sullivan PS. Factors associated with returning at-home specimen collection kits for HIV testing among internet-using men who have sex with men. J Int Assoc Provid AIDS Care 2016 Dec;15(6):463-469. [doi: 10.1177/2325957416668579] [Medline: 27635015]

29. McDade TW, Williams S, Snodgrass JJ. What a drop can do: dried blood spots as a minimally invasive method for integrating biomarkers into population-based research. Demography 2007 Nov;44(4):899-925. [Medline: 18232218] 
30. Chace DH, Hannon WH. Filter paper as a blood sample collection device for newborn screening. Clin Chem 2016 Mar;62(3):423-425 [FREE Full text] [doi: 10.1373/clinchem.2015.252007] [Medline: 26797689]

31. Mei JV, Alexander JR, Adam BW, Hannon WH. Use of filter paper for the collection and analysis of human whole blood specimens. J Nutr 2001 May;131(5):1631S-1636S. [doi: 10.1093/jn/131.5.1631S] [Medline: 11340130]

32. Snijdewind IJ, van Kampen JJ, Fraaij PL, van der Ende ME, Osterhaus AD, Gruters RA. Current and future applications of dried blood spots in viral disease management. Antiviral Res 2012 Mar;93(3):309-321. [doi:

10.1016/j.antiviral.2011.12.011] [Medline: 22244848]

33. Parker SP, Cubitt WD. The use of the dried blood spot sample in epidemiological studies. J Clin Pathol 1999 Sep;52(9):633-639 [FREE Full text] [Medline: 10655983$]$

34. Katz DA, Golden MR, Stekler JD. Use of a home-use test to diagnose HIV infection in a sex partner: a case report. BMC Res Notes 2012 Aug 15;5:440 [FREE Full text] [doi: 10.1186/1756-0500-5-440] [Medline: 22894746]

35. Stekler JD, Ure G, Dragavon J, Chang M, Coombs RW. Detection of HIV RNA in dried blood spots and oral fluids. AIDS 2017 May 15;31(8):1191-1193. [doi: 10.1097/QAD.0000000000001477] [Medline: 28358729]

36. Cohen MS, Chen YQ, McCauley M, Gamble T, Hosseinipour MC, Kumarasamy N, HPTN 052 Study Team. Prevention of HIV-1 infection with early antiretroviral therapy. N Engl J Med 2011 Aug 11;365(6):493-505 [FREE Full text] [doi: 10.1056/NEJMoa1105243] [Medline: 21767103]

37. Rodger AJ, Cambiano V, Bruun T, Vernazza P, Collins S, van Lunzen J, PARTNER Study Group. Sexual activity without condoms and risk of HIV transmission in serodifferent couples when the hiv-positive partner is using suppressive antiretroviral therapy. JAMA 2016 Jul 12;316(2):171-181. [doi: 10.1001/jama.2016.5148] [Medline: 27404185]

38. Bavinton B, Grinsztejn B, Phanuphak N, Jin F, Zablotska I, Prestage G, The Opposites Attract Study Group. HIV treatment prevents HIV transmission in male serodiscordant couples in Australia, Thailand and Brazil. J Int AIDS Soc 2017;20(Suppl 5):22253 [FREE Full text] [doi: 10.7448/IAS.20.6.22253] [Medline: 28953320]

39. McCray E, Mermin J. Cdc.gov. 2017 Sep 27. Dear Colleague URL: https://www.cdc.gov/hiv/library/dcl/dcl/092717. html[WebCite Cache ID 6ynbJ0e5L]

40. Fauci A. Plenary Session: Federal Perspectives on Research, Prevention, and Treatment. 2017 Sep 9 Presented at: United States Conference on AIDS; 2017; Washington, DC.

41. Centers for Disease Control and Prevention. Cdc.gov. 2017. Evidence of HIV treatment and viral suppression in preventing the sexual transmission of HIV URL: https://www.cdc.gov/hiv/pdf/risk/art/cdc-hiv-art-viral-suppression.pdf [accessed 2018-04-18] [WebCite Cache ID 6ynbivHj3]

42. The Lancet HIV. U=U taking off in 2017. Lancet HIV 2017 Dec;4(11):e475. [doi: 10.1016/S2352-3018(17)30183-2] [Medline: 29096785]

43. Mustanski B, Ryan DT, Remble TA, D'Aquila RT, Newcomb ME, Morgan E. Discordance of self-reported and laboratory measures of HIV viral load among young men who have sex with men and transgender women in Chicago: implications for epidemiology, care, and prevention. AIDS Behav 2018 Apr 10. [doi: 10.1007/s10461-018-2112-7] [Medline: 29637386]

44. Sánchez-Taltavull D, Alarcón T. Stochastic modelling of viral blips in HIV-1-infected patients: effects of inhomogeneous density fluctuations. J Theor Biol 2015 Apr 21;371:79-89. [doi: 10.1016/j.jtbi.2015.02.001] [Medline: 25681146]

45. Fidler S, Olson AD, Bucher HC, Fox J, Thornhill J, Morrison C, et al. Virological blips and predictors of post treatment viral control after stopping ART started in primary HIV infection. J Acquir Immune Defic Syndr 2017 Feb 1;74(2):126-133 [FREE Full text] [doi: 10.1097/QAI.0000000000001220] [Medline: 27846036]

46. Farmer A, Wang X, Ganesan A, Deiss RG, Agan BK, O'Bryan TA, et al. Factors associated with HIV viral load "blips" and the relationship between self-reported adherence and efavirenz blood levels on blip occurrence: a case-control study. AIDS Res Ther 2016;13:16 [FREE Full text] [doi: 10.1186/s12981-016-0100-4] [Medline: 27006682]

47. Podsadecki TJ, Vrijens BC, Tousset EP, Rode RA, Hanna GJ. Decreased adherence to antiretroviral therapy observed prior to transient human immunodeficiency virus type 1 viremia. J Infect Dis 2007 Dec 15;196(12):1773-1778. [doi:

10.1086/523704] [Medline: 18190257]

48. Cassol S, Gill MJ, Pilon R, Cormier M, Voigt RF, Willoughby B, et al. Quantification of human immunodeficiency virus type 1 RNA from dried plasma spots collected on filter paper. J Clin Microbiol 1997 Nov;35(11):2795-2801 [FREE Full text] [Medline: $\underline{\text { 9350736] }}$

49. Alvarez-Muñoz MT, Zaragoza-Rodríguez S, Rojas-Montes O, Palacios-Saucedo G, Vázquez-Rosales G, Gómez-Delgado A, et al. High correlation of human immunodeficiency virus type-1 viral load measured in dried-blood spot samples and in plasma under different storage conditions. Arch Med Res 2005;36(4):382-386. [doi: 10.1016/j.arcmed.2005.03.010] [Medline: 15950079]

50. Garrido C, Zahonero N, Corral A, Arredondo M, Soriano V, de Mendoza C. Correlation between human immunodeficiency virus type 1 (HIV-1) RNA measurements obtained with dried blood spots and those obtained with plasma by use of Nuclisens EasyQ HIV-1 and Abbott RealTime HIV load tests. J Clin Microbiol 2009 Apr;47(4):1031-1036 [FREE Full text] [doi: 10.1128/JCM.02099-08] [Medline: 19193847]

51. Manak MM, Hack HR, Shutt AL, Danboise BA, Jagodzinski LL, Peel SA. tability of Human Immunodeficiency Virus serological markers in samples collected as HemaSpot and Whatman 903 Dried Blood Spots. J Clin Microbiol 2018 Oct;56(10) [FREE Full text] [doi: 10.1128/JCM.00933-18] [Medline: 30045869] 
52. Marconi A, Balestrieri M, Comastri G, Pulvirenti FR, Gennari W, Tagliazucchi S, et al. Evaluation of the Abbott Real-Time HIV-1 quantitative assay with dried blood spot specimens. Clin Microbiol Infect 2009 Jan;15(1):93-97 [FREE Full text] [doi: 10.1111/j.1469-0691.2008.02116.x] [Medline: 19220340]

53. Neogi U, Gupta S, Rodridges R, Sahoo PN, Rao SD, Rewari BB, et al. Dried blood spot HIV-1 RNA quantification: a useful tool for viral load monitoring among HIV-infected individuals in India. Indian J Med Res 2012 Dec;136(6):956-962 [FREE Full text] [Medline: 23391790]

54. Dize L, Spielberg F, Valsamakis A, Lucic D, Hamburg N, Hidalgo J, et al. Evaluation of an open mode protocol for HIV-1 RNA quantification in dried blood spots on the Abbot m2000sp platform. 2016 May Presented at: Clinical Virology Symposium; 2016; Daytona Beach, FL URL: https://www.spotonsciences.com/site/wp-content/uploads/ JHU-Viral-Load-CVS-Poster251-2016-.pdf

55. Fajardo E, Metcalf CA, Chaillet P, Aleixo L, Pannus P, Panunzi I, et al. Prospective evaluation of diagnostic accuracy of dried blood spots from finger prick samples for determination of HIV-1 load with the NucliSENS Easy-Q HIV-1 version 2.0 assay in Malawi. J Clin Microbiol 2014 May;52(5):1343-1351 [FREE Full text] [doi: 10.1128/JCM.03519-13] [Medline: 24501032]

56. Johannessen A, Garrido C, Zahonero N, Sandvik L, Naman E, Kivuyo SL, et al. Dried blood spots perform well in viral load monitoring of patients who receive antiretroviral treatment in rural Tanzania. Clin Infect Dis 2009 Sep 15;49(6):976-981. [doi: 10.1086/605502] [Medline: 19663598]

57. Rottinghaus EK, Ugbena R, Diallo K, Bassey O, Azeez A, Devos J, et al. Dried blood spot specimens are a suitable alternative sample type for HIV-1 viral load measurement and drug resistance genotyping in patients receiving first-line antiretroviral therapy. Clin Infect Dis 2012 Apr;54(8):1187-1195. [doi: 10.1093/cid/cis015] [Medline: 22412066]

58. van Deursen P, Oosterlaken T, Andre P, Verhoeven A, Bertens L, Trabaud MA, et al. Measuring human immunodeficiency virus type 1 RNA loads in dried blood spot specimens using NucliSENS EasyQ HIV-1 v2.0. J Clin Virol 2010 Feb;47(2):120-125. [doi: 10.1016/j.jcv.2009.11.021] [Medline: 20018560]

\author{
Abbreviations \\ ART: antiretroviral therapy \\ DBS: dried blood spot \\ DBS kit: HemaSpot-HF device \\ IRB: institutional review board \\ IQR: interquartile range \\ M-Spot: Mailed-Spot \\ MSM: men who have sex with men \\ VL: HIV-1 RNA viral load
}

Edited by T Sanchez; submitted 23.04.18; peer-reviewed by L Hightow-Weidman, C Khosropour, S Masciotra, K Card; comments to
author 07.06.18; revised version received 10.08.18; accepted 16.08.18; published 01.11.18
Please cite as:
Hirshfield S, Teran RA, Downing Jr MJ, Chiasson MA, Tieu HV, Dize L, Gaydos CA
Quantification of HIV-1 RNA Among Men Who Have Sex With Men Using an At-Home Self-Collected Dried Blood Spot Specimen:
Feasibility Study
JMIR Public Health Surveill 2018;4(4):e10847
URL: $\underline{\text { http://publichealth.jmir.org/2018/4/e10847/ }}$
doi: $\underline{10.2196 / 10847}$
PMID: $\underline{30389648}$

(C)Sabina Hirshfield, Richard A Teran, Martin J Downing Jr, Mary Ann Chiasson, Hong-Van Tieu, Laura Dize, Charlotte A Gaydos. Originally published in JMIR Public Health and Surveillance (http://publichealth.jmir.org), 01.11.2018. This is an open-access article distributed under the terms of the Creative Commons Attribution License (https://creativecommons.org/licenses/by/4.0/), which permits unrestricted use, distribution, and reproduction in any medium, provided the original work, first published in JMIR Public Health and Surveillance, is properly cited. The complete bibliographic information, a link to the original publication on http://publichealth.jmir.org, as well as this copyright and license information must be included. 